\title{
Corrosion Control of Aluminum Surfaces by Polypyrrole Films: Influence of Electrolyte
}

\author{
Andréa Santos Liu ${ }^{\mathrm{a}, \mathrm{b} *}$, Maria Auxiliadora Silva Oliveira ${ }^{\mathrm{a}}$ \\ ${ }^{a}$ Departamento de Química, Instituto Tecnológico de Aeronáutica - ITA, \\ Centro Técnico Aeroespacial - CTA, Praça Marechal Eduardo Gomes, 50, \\ 12228-900 São José dos Campos - SP, Brazil \\ ${ }^{\mathrm{b}}$ Instituto de Pesquisa e Desenvolvimento, Universidade do Vale do Paraíba-UNIVAP, \\ Av. Shishima Hifumi, 2911, 12244-000 São José dos Campos - SP, Brazil
}

Received: March 13, 2007; Revised: May 31, 2007

\begin{abstract}
Polypyrrole (PPy) films were galvanostatically deposited on 99.9 wt. (\%) aluminum electrodes from aqueous solutions containing each carboxylic acid: tartaric, oxalic or citric. Scanning Electron Microscopy (SEM) was used to analyze the morphology of the aluminum surfaces coated with the polymeric films. It was observed that the films deposited from tartaric acid medium presented higher homogeneity than those deposited from oxalic and citric acid. Furthermore, the corrosion protection of aluminum surfaces by PPy films was also investigated by potentiodynamic polarization experiments.
\end{abstract}

Keywords: polypyrrole, electrolyte, aluminum, corrosion

\section{Introduction}

Polypyrrole (PPy) is a conducting polymer that has been investigated for applications in batteries, sensors, membranes and protection of metals against corrosion ${ }^{1-4}$.

The polymer can be prepared by chemical and electrochemical methods from aqueous or organic media. The electrochemical process is more advantageous since film properties such as thickness and conductivity can be controlled by the synthesis parameters (current density, substrate, $\mathrm{pH}$, nature and concentration of electrolyte $)^{5,6}$.

The electrolytic species can participate as dopant and incorporate into the polymeric films ${ }^{7}$. The anions are indispensable to compensate the conducting polymer charges. The structure and the concentration of these anions affect the conductivity, the stability and the morphology of the PPy films ${ }^{8}$. It was found that the films doped with aromatic organic anions are electrically more conductive than those doped with inorganic anions. This behavior has been ascribed to a better superposition of the molecular orbitals of the dopant with the $\pi$ atomic orbitals of the carbon in the polymeric chain. It was also observed that PPy films doped with organic species are more adherent and uniform than those doped with inorganic anions ${ }^{9}$.

In a previous work, we have reported that adherent and homogeneous PPy films were galvanostatically electrodeposited on aluminum surfaces from aqueous solutions containing pyrrole and tartaric acid, $\mathrm{pH}$ 2, applying current density of $2.5 \mathrm{~mA} . \mathrm{cm}^{-2}{ }^{10}$.

In this work, the influence of aliphatic organic acids on the electrodeposition of PPy films on 99.9 wt. (\%) aluminum surfaces was investigated. The polymeric films were galvanostatically deposited at $2.5 \mathrm{~mA} . \mathrm{cm}^{-2}$ from aqueous solutions containing, respectively tartaric, oxalic or citric acid. The morphology of the PPy films was characterized by Scanning Electron Microscopy (SEM). Additionally, the efficiency of the polymeric films on protecting aluminum surfaces against corrosion was investigated by polarization curves in chloride medium.

\section{Experimental}

The electrochemical experiments were performed at room temperature in a cell containing three electrodes. The working electrode was a 99.9 wt. (\%) aluminum rod, embedded in Teflon ${ }^{\circledR}$, leaving a disc-shaped exposed area of $0.53 \mathrm{~cm}^{2}$. The reference electrode was a saturated $\mathrm{Ag} / \mathrm{AgCl}, \mathrm{Cl}^{-}$electrode, and the auxiliary electrode was a platinum wire. These experiments were carried out by a Potentiostat / Galvanostat MQPG-01 Model (Microquímica).

The PPy films were galvanostatically deposited from aqueous solutions containing $0.5 \mathrm{~mol} . \mathrm{L}^{-1}$ pyrrole (Aldrich, distilled before using) + 0.2 mol. $\mathrm{L}^{-1}$ of each aliphatic acid: tartaric acid (Reagen), oxalic acid (Fisher) or citric acid (Reagen). The $\mathrm{pH}$ of each solution was adjusted to 2.0 by addition of $\mathrm{NaOH}$ (Synth). The applied current density was $2.5 \mathrm{~mA} \cdot \mathrm{cm}^{-2}$.

Before each electrochemical experiment, the aluminum surfaces were polished with emery paper (400, 600 and 1000 grades), 3- $\mu \mathrm{m}$ alumina water suspension and rinsed with distilled water.

The morphology of aluminum surfaces coated with PPy films was analyzed using a Jeol JXA-840A Scanning Electron Microscope (SEM). The micrographs were obtained using an electron beam of $15 \mathrm{keV}$.

FTIR spectroscopy was used to analyze the PPy films composition. The spectra were obtained using a spectrometer model SPECTRUM-2000 (Perkin Elmer). The analysis conditions were: wavenumber range of $4000-400 \mathrm{~cm}^{-1}, 4 \mathrm{~cm}^{-1}$ resolution, 40 scans, and room temperature $\left(25^{\circ} \mathrm{C}\right)$. $\mathrm{KBr}$ pellets were prepared with the PPy films. The films were dried at vacuum and then carefully removed from aluminum surfaces with aid of a spatula.

The corrosion resistance of aluminum surfaces, polished and coated with PPy films, was investigated using the potentiodynamic polarization technique. The surfaces were exposed to a $0.1 \mathrm{~mol} . \mathrm{L}^{-1} \mathrm{NaCl}$ aqueous solution ( $\mathrm{pH}$ 5.9), not stirred and open to the atmosphere. The polarization curves were obtained starting from the open circuit potential (OCP) and varying the potential, respectively, up to $400 \mathrm{mV}$ (anodic branch of the Tafel plot) and down to $-400 \mathrm{mV}$ (cathodic branch of the Tafel plot). The potential scan rate was $5 \mathrm{mV} \cdot \mathrm{s}^{-1}$.

The corrosion potential $\left(\mathrm{E}_{\text {corr }}\right)$ and the corrosion current densitiy $\left(\mathrm{j}_{\text {corr }}\right)$ were obtained from the Tafel plots. The $\mathrm{E}_{\text {corr }}$ is the potential 
at which the current density is zero. The $\mathrm{j}_{\text {corr }}$ was determined by extrapolation, to $\mathrm{E}_{\text {corr }}$, from linear parts of the anodic and cathodic branches of the Tafel plots ${ }^{11}$.

\section{Results and Discussion}

Figure 1 presents the cronopotentiometric curves for the electrodeposition of PPy on aluminum surfaces from aqueous solutions containing $0.5 \mathrm{~mol} . \mathrm{L}^{-1}$ pyrrole $+0.2 \mathrm{~mol} . \mathrm{L}^{-1}$ each organic acid and $\mathrm{pH}$ 2.0. The applied current density was $2.5 \mathrm{~mA} . \mathrm{cm}^{-2}$ and maintaining the same deposition charge $\left(9.10^{4} \mathrm{C} . \mathrm{m}^{-2}\right)$.

It was observed that the steady-potential value at which occurs the growth of PPy films, decreases in the following sequence: citric acid $>$ tartaric acid $>$ oxalic acid. This behavior has been associated to aluminum oxide layer characteristics.

The proposed mechanism to explain the PPy formation on aluminum surfaces considers the growth of polymer nucleus through pores and/or cracks on the oxide layer ${ }^{7,12,13}$. Consequently, a more compact oxide layer, with fewer defects, should difficult the PPy growth. The adsorption of stable complexes at the interface aluminum oxide/electrolytic solution may result in a more compact and resistant oxide layer ${ }^{14,15}$. The formation of complexes between aluminum species and the organic acids occurs through carboxylic groups ${ }^{16}$.

Among the used aliphatic acid, the citric acid presents higher number of active sites to complexing with aluminum species at the interface oxide/solution ${ }^{16}$. Consequently the oxide layer is more compact and thicker in citric acid medium and can explain the PPy growth at higher potential. Figure 2 presents the structures of the organic acids used as electrolytes. Studies were being performed in our laboratory to verify the behavior of these acids in the anodization of aluminum surfaces and their role as corrosion inhibitors.

The PPy films deposited from each aliphatic acid were removed from aluminum surfaces and characterized by FTIR spectroscopy. The results are presented in Figure 3.

The absorption bands at 1170 and $1630 \mathrm{~cm}^{-1}$ in the FTIR spectra of PPy films electrodeposited from oxalic and citric acid media have been attributed, respectively, to the bipolaronic species and to carbonyl groups that are formed by overoxidation ${ }^{17,18}$. Similar bands were not observed in the FTIR spectrum of PPy film electrodeposited

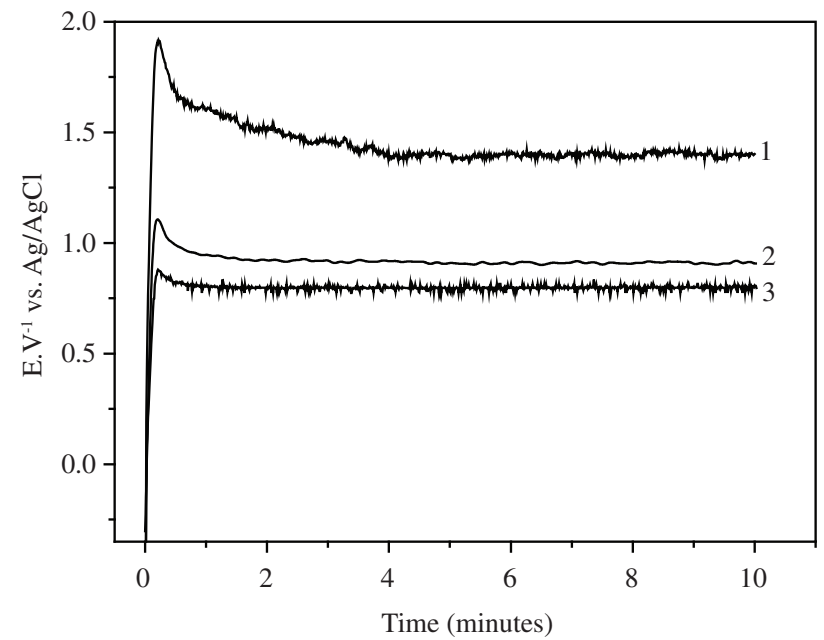

Figure 1. Potential transient for PPy electrodeposition on aluminum surfaces from aqueous solutions containing $0.5 \mathrm{~mol} . \mathrm{L}^{-1}$ pyrrole and $0.2 \mathrm{~mol} . \mathrm{L}^{-1}$ of each electrolyte: 1) citric acid; 2) tartaric acid; and 3) oxalic acid. from tartaric acid medium, which indicates that the polymer deposited from this medium presents lower overoxidation degree than the films formed in oxalic or citric acids.

The overoxidation is an irreversible degradation process that results in the shortening of the polymer chain length and/or formation of defects and pores along the PPy chain ${ }^{19}$. Figure 4 shows the sequence of reactions that occur during the overoxidation.

The spectrum of PPy film deposited from tartaric acid (Figure 3a) presents a very strong band at $1700 \mathrm{~cm}^{-1}$ and a medium band at<smiles>O=C(O)C(=O)O</smiles>

$\mathrm{O}$<smiles>O=C(O)C(O)C(O)C(=O)O</smiles><smiles>O=C(O)CC(O)(CC(=O)O)C(=O)O</smiles>

Figure 2. Structures of organic acids used as electrolytes to deposit the PPy films.

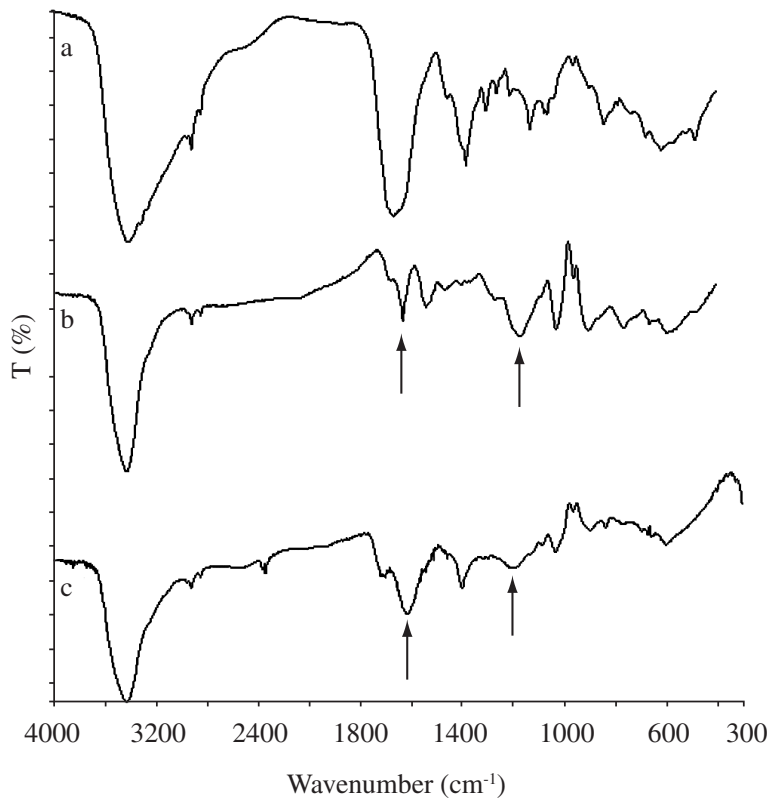

Figure 3. FTIR spectra of PPy films electrodeposited from aqueous solutions containing 0.5 mol. $\mathrm{L}^{-1}$ pyrrole $+0.2 \mathrm{~mol} \mathrm{~L}^{-1}$ of each electrolyte: a) tartaric acid; b) oxalic acid; and c) citric acid. 
$1134 \mathrm{~cm}^{-1}$, attributed to the carboxylic and hydroxyl groups, respectively ${ }^{20,21}$. These bands are associated to the tartaric acid, which incorporates the polymeric film via doping during the synthesis of the PPy. Since the overoxidation also results in the dedoping of conducting polypyrrole ${ }^{19}$, it can concluded that the PPy film deposited in tartaric acid is not overoxidized.

Scanning Electron Microscopy was used to investigate the morphology of the PPy films electrodeposited from each aliphatic acid. The obtained micrographs are presented in Figure 5.

The PPy films present a cauliflower-like structure constituted by micro-spherical grains. It has been reported that this cauliflower structure is related to the dopant intercalation difficulty in the disordered polymeric chain ${ }^{22}$. The PPy film formed in tartaric acid medium was more homogeneous than the films deposited in media containing the other acids.

Figure 5 also shows that the cauliflower structure in the PPy films deposited from oxalic acid was smaller than those observed in the PPy films formed in citric acid, which presented a smaller structure than the PPy electrodeposited from tartaric acid. The smallest size of cauliflower structure has been attributed to the occurrence of overoxidation process during the synthesis of PPy.

The corrosion resistance of aluminum surfaces coated with PPy films was investigated in chloride containing medium

Figure 6 shows the potentiodynamic polarization curves, in 0.1 mol. $\mathrm{L}^{-1} \mathrm{NaCl}$ aqueous solutions, not stirred, $\mathrm{pH}$ 5.9, for just polished aluminum surfaces and for surfaces coated with PPy films deposited galvanostatically at $2.5 \mathrm{~mA} . \mathrm{cm}^{-2}$ in the different electrolytes. The potential scan rate was $5 \mathrm{mV} \cdot \mathrm{s}^{-1}$.

The corrosion potential of aluminum surfaces coated with polymeric films shifted to less negative values and the anodic current densities of these surfaces were smaller than those observed to just polished aluminum surfaces. These observations can be taken as an indication that aluminum surfaces coated with PPy films are more resistant to corrosion than uncoated surfaces. Furthermore, after polarization curves, it was noted pits on the uncoated aluminum surface, which presented pit potential at $-0.69 \mathrm{~V}$ (Figure 6 , curve 1 ). Pit potential was not observed in polarization curves for aluminum surfaces coated by PPy films.

The cathodic current densities, however, were higher for aluminum surfaces coated with PPy than for uncoated aluminum surfaces. The cathodic current densities increased in the sequence: uncoated surfaces < surface coated with PPy deposited in citric acid $<$ surface coated with PPy deposited in tartaric acid $\cong$ surface coated with PPy deposited in oxalic acid. Similar results have been shown in literature and have been associated to reduction reaction of polymeric matrix, which contributes to increasing the cathodic currents 23,24<smiles>C/C=C(/[NH-])c1ccc(C)[nH]1</smiles>

$\mathrm{H}$<smiles>C=CC(C)=CC</smiles><smiles>CCc1ccc[nH]1</smiles>

$\mathrm{H}_{2} \mathrm{O}$

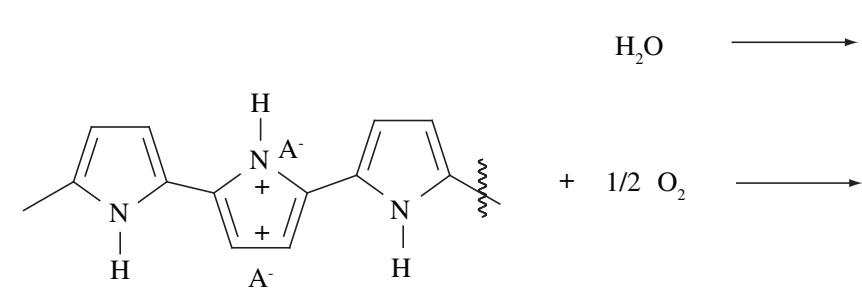

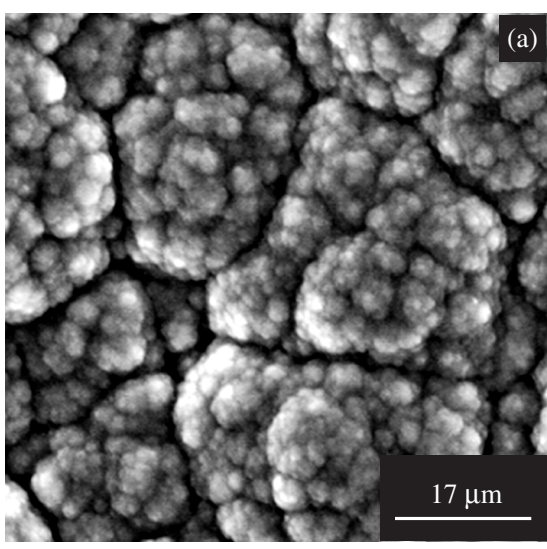
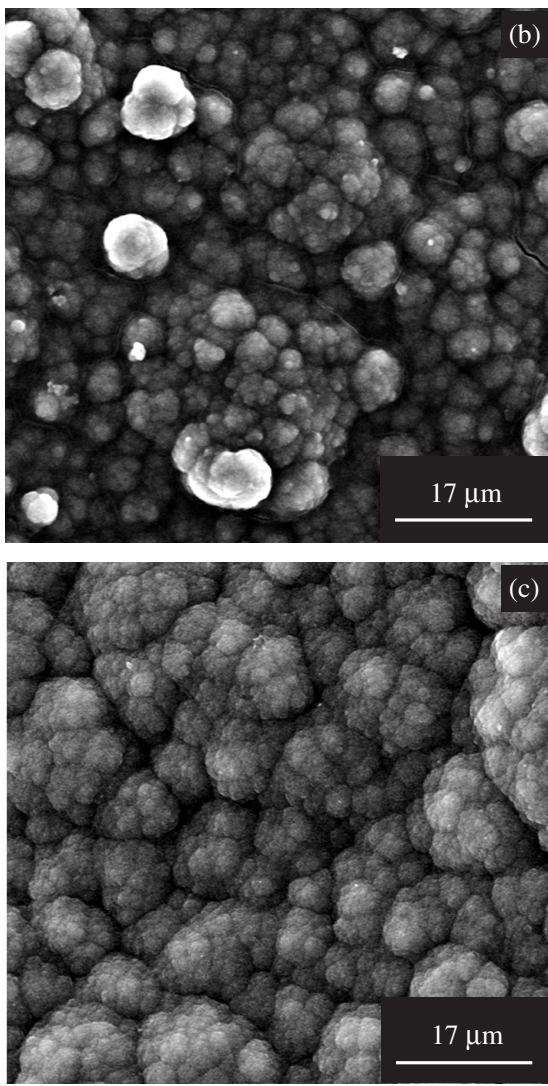

Figure 5. SEM micrographs of aluminum surfaces coated with PPy films deposited galvanostatically at $2.5 \mathrm{~mA} . \mathrm{cm}^{-2}$ from aqueous media containing 0.5 mol. $\mathrm{L}^{-1}$ pyrrole +0.2 mol. $\mathrm{L}^{-1}$ of each electrolyte: a) tartaric acid; b) oxalic acid; and c) citric acid.

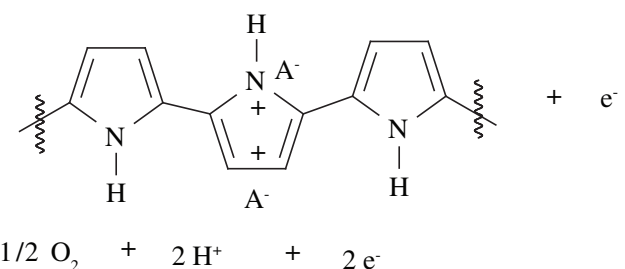

Figure 4. Reactions that occur during the overoxidation of the PPy films.

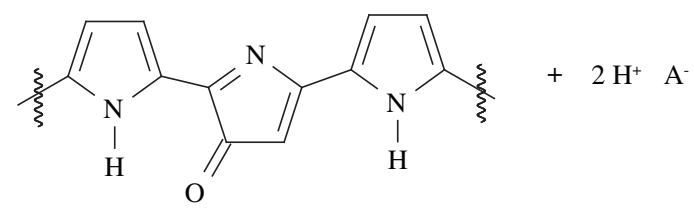


The possible chemical reactions occurring onto aluminum surfaces coated with PPy during the polarizations experiments are represented bellow ${ }^{25}$.

Anodic reactions

$\mathrm{Al} \rightarrow \mathrm{Al}^{+3}+3 \mathrm{e}^{-}$

Overoxidation of polymer

$\mathrm{PPy}_{\text {undoped }} \rightarrow \mathrm{PPy}_{\text {doped }}+\mathrm{ne}^{-}$

Cathodic reactions

$$
\begin{aligned}
& 2 \mathrm{H}_{2} \mathrm{O}+\mathrm{O}_{2}+4 \mathrm{e}^{-} \rightarrow 4 \mathrm{OH}^{-} \\
& \mathrm{PPy}_{\text {doped }}+\mathrm{ne}^{-} \rightarrow \mathrm{PPy}_{\text {undoped }}
\end{aligned}
$$

The electrochemical parameters obtained from the polarization curves shown in Figure 6 are presented in Table 1.

The corrosion current densities of the aluminum surfaces coated with PPy films were higher than those observed for uncoated surfaces. The occurrence of redox reactions in the polymeric matrix can also contribute to increasing the corrosion current densities values.

However, if the anodic current densities are used as criterion to determine the corrosion protection afforded by the PPy films, it would be possible to affirm that aluminum surfaces coated with the polymeric films are less susceptible to corrosion processes than just polished ones. Additionally, one could say that PPy films electrodeposited from tartaric acid offer better corrosion performance. This result is ascribed to the highest homogeneity of these films (SEM micrographs).

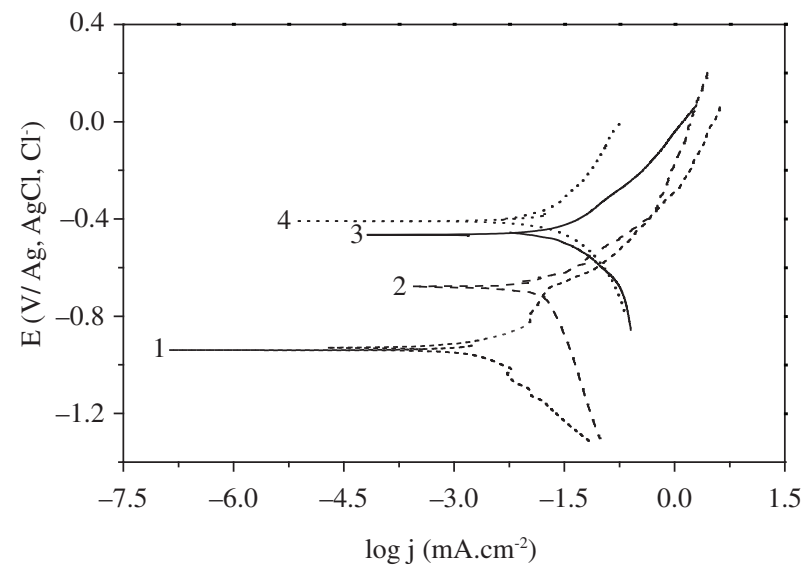

Figure 6. Polarization curves for aluminum surface: 1) just polished; coated with PPy films electrodeposited galvanostatically $\left(2.5 \mathrm{~mA} . \mathrm{cm}^{-2}\right)$ from pyrrole aqueous solutions containing, respectively, 0.2 mol. $\mathrm{L}^{-1}$ acid: 2 ) citric; 3) oxalic; and 4) tartaric.
The presence of the voids among the cauliflower structure of the films deposited in oxalic and citric acid (Figure 5) allows the penetration of chloride ions (aggressive species) favoring the corrosion process.

It was also observed that the aluminum surfaces coated by PPy films deposited in tartaric acid presented smaller amount of pits after polarization experiments in chloride medium.

\section{Conclusion}

Considering the anodic current densities in the potentiodynamic polarization curves as a criterion to determining the corrosion protection afforded by the PPy films, it would be possible to affirm that aluminum surfaces coated with the polymeric films are less susceptible to corrosion process than just polished ones. Additionally, it could be also said that PPy films electrodeposited in tartaric acid medium are the ones that offer better corrosion performance. This result can be explained by the highest homogeneity of the polymeric films formed in this medium (SEM micrographs).

The PPy films deposited from oxalic or citric acid were more susceptible to the overoxidation process than those films formed in tartaric acid. This fact was demonstrated in the SEM micrographs and by the presence of the bands attributed, respectively, to bipolaronic species and to carbonyl groups on the FTIR spectra.

The overoxidation process is responsible by pores and defects along the polymeric structure that allow the penetration of chloride ions (aggressive species) favoring the corrosion process.

\section{Acknowledgments}

The authors thank the Fundação de Amparo à Pesquisa do Estado de São Paulo (FAPESP) for the financial support and the Alcoa Alumínio SA, São Luis, Maranhão, Brazil.

\section{References}

1. Ingram MD, Staesche H, Ryder KS. Activated polypyrrole electrodes for high power supercapacitor applications. Solid State Ionics. 2004; 169(1):51-57.

2. Ameer Q, Adeloju SB. Polypyrrole-based eletronic noses for environment and industrial analysis. Sens. Actuators B. 2005; 106(2):541-552.

3. Tallman DE, Sokins G, Dominis A, Wallace GG. Electroactive conducting polymers for corrosion control. J. Solid State Electrochem. 2002; 6:73-84.

4. Tramontina J, Machado G, Azambuja DS, Pianicki CMS, Samios D. Removal of $\mathrm{Cd}^{+2}$ from aqueous solutions onto polypyrrole coated reticulated vitreous carbon electrodes. Mat. Res. 2001; 4(3):95-200.

5. Wencheng S, Iroh JO. Effects of electrochemical process parameters on the synthesis and properties of polypyrrole coatings on steel. Synth. Met. 1998; 95(3):159-167.

6. Wang LX, Li XG, Yang YL. Preparation, properties and applications of polypyrrole. React. Funct. Polymers. 2001; 47(2):125-139.

7. Naoi K, Takeda M, Kanno H, Sakakura M, Shimada A. Simultaneous electrochemical formation of $\mathrm{Al}_{2} \mathrm{O}_{3}$ / polypyrrole layers: effect of electrolyte anion formation process. Electrochim. Acta. 2000; 45(20):3413-3421.

Table 1. Electrochemical parameters obtained for aluminum surfaces, just polished and coated with PPy films electrodeposited from aqueous solution containing each aliphatic acid, exposed to a $0.1 \mathrm{~mol} . \mathrm{L}^{-1} \mathrm{NaCl}$ aqueous solutions.

\begin{tabular}{lccc}
\hline \multicolumn{1}{c}{ Aluminum surfaces } & $\begin{array}{c}\text { Time to reach the OCP in the } \\
\text { chloride medium (h) }\end{array}$ & $\mathrm{E}_{\text {corr }}\left(\mathrm{V} / \mathrm{Ag}, \mathrm{AgCl}, \mathrm{Cl}^{-}\right)$ & $\mathrm{j}_{\text {corr }}\left(\mathrm{mA}^{\left.-\mathrm{cm}^{-2}\right)}\right.$ \\
\hline Uncoated & 48 & -0.93 & 0.0023 \\
Coated with PPy deposited in tartaric acid & 24 & -0.41 & 0.018 \\
Coated with PPy deposited in oxalic acid & 24 & -0.46 & 0.024 \\
Coated with PPy deposited in citric acid & 24 & -0.69 & 0.014 \\
\hline
\end{tabular}


8. Mohammad F. Comparative studies on diffusion behavior of electrochemically prepared polythiophene and polypyrrole: effect of ionic size of dopant. Synth. Met. 1999; 99(2):149-154.

9. Kaplin DA, Qutubuddin S. Electrochemical synthetized polypyrrole films: effect of polymerization potential and electrolyte type. Polymer. 1995; 36(6):1275-1286.

10. Liu AS, Oliveira MAS. Electrodeposition of polypyrrole films on aluminum surfaces from tartrate aqueous solution. J. Braz.Chem. Soc. 2007; 18(1):143-152.

11. ASTM G 102-89, "Practice for Calculation of Corrosion Rates and Related Information from Electrochemical Measurements"; 1994.

12. Saidman SB, Bessone JB. Electrochemical preparation and characterization of polypyrrole on aluminum in aqueous solution. J. Electroanal. Chem. 2002; 521(1):87-94.

13. Tsai ML, Chen PJ, Do JS. Preparation and characterization of PPy / $\mathrm{Al}_{2} \mathrm{O}_{3} / \mathrm{Al}$ used as solid-state capacitor. J. Power Sources. 2004; 133(2):302-311.

14. Mazhar AA, Arab ST, Noor EA. Electrochemical behavior of Al-Si alloys in acid alkaline media. Bull. Electrochem. 2001; 17:449-458.

15. Bessone JB, Salinas DR, Mayer CE, Ebert M, Lorenz WJ. An EIS study of aluminum barrier-type oxide films formed in different media. Electrochim. Acta. 1992; 37(12):2283-2290.

16. Muller B. Citric acid as corrosion inhibitor for aluminum pigment. Cor ros. Sci. 2004; 46(1):159-167.

17. Mazeikien R, Malinauskas A. Kinetics of the electrochemical degradation of polypyrrole. Polym. Degrad. Stab. 2002; 75(2):255-258.
18. Rodriguez I, Scharifker BR, Mostany J. In situ FTIR study of redox and overoxidation process in polypyrrole films. J. Electroanal. Chem. 2000; 491(1):117-125.

19. Li Y, Qian R. Electrochemical overoxidation of conducting polypyrrole nitrate film in aqueous solutions. Electrochim. Acta. 2000; 45(11):1727-1731.

20. Marchewka MK, Debrus S, Pietraszko A, Barnes AJ, Ratajczak H. Crystal structure, vibration spectra and nonlinear optical properties of L-tartrate. J. Molecular Structure. 2003; 656(1):265-273.

21. Hon YM, Fung KZ, Lin SP, Hon MH. Effect of metal ion sources on synthesis and electrochemical performance of spinel $\mathrm{LiMn}_{2} \mathrm{O}$ using tartaric acid. J. Solid State Chem. 2002; 163(1):231-238.

22. Bazzaoui M, Martins L, Bazzaoui EA, Martins JI. New single step electrosynthesis process of homogeneous and strongly adherent polypyrrole films on iron electrodes in aqueous medium. Electrochim. Acta. 2002; 47(18):2953-2962.

23. Breslin CB, Fenelon AM, Conroy KG. Surface engineering: corrosion protection using conducting polymers. Materials and Design. 2005; 26(3):233-237

24. Vilca DH, Moraes SR, Motheo AJ. Anodic treatment of aluminum in nitric acid containing aniline, previous to deposition of polyaniline and its role on corrosion. Synth. Met. 2004; 140(1):23-27.

25. Ocon P, Cristobal AB, Herrasti P, Fatas E. Corrosion performance of conducting polymer coating applied on mild steel. Corros. Sci. 2005; 47(3):649-662. 